\title{
Farewell and Thanks to Dr Carl Mattacola
}

Undoubtedly, the Journal of Sport Rehabilitation (JSR) has prospered under the direction of Dr Carl Mattacola as Editor-inChief over the last 12-plus years. JSR's reputation and impact in sport rehabilitation have grown under Carl's steadfast and strategic leadership. Many achievements have marked Carl's tenure; a few of the journal's noteworthy successes include increased circulation and visibility, the introduction of new manuscript categories (Critically Appraised Topics and Technical Reports), the spearheading of innovative thematic issues, and the dramatic rise of the journal's Impact Factor.

In 2007, the year Carl took over from Dr Buz Swanik, JSR had recently transitioned to a new online submission system, Manuscript Central, which was used to manage the peer review process for 73 submissions in his first year. At that time, JSR was published quarterly in a $6 \times 9$-in format, was just accepted for indexing by PubMed, and had an Impact Factor of 0.283. Today, JSR manages more than 450 manuscript submissions per year, promotes open access Critically Appraised Topics and Technical Reports in addition to traditional manuscript categories (eg, Original Research studies, Systematic Reviews, etc), has nearly 2000 followers on Twitter, and publishes 8 issues per year using an $8.5 \times 11$-in format. The numbers tell a story: In Carl's first year, the journal published 32 articles, and in his final full year as Editor-in-Chief, in 2018, JSR published 100 articles. And the Impact Factor has risen greater than 6-fold to its current 1.811.

Those numbers are impressive and clearly demonstrate JSR's growth and success, but there is more to the story. Those who know Carl are quick to emphasize his vision, open-mindedness, and fortitude, while recognizing his collegiality and professionalism, warm smile, and friendly demeanor. It is those traits that have aided Carl so well in encouraging the journal's growth throughout his tenure.

Personally, I will always be grateful for the phone call I received from Carl when I was a young faculty member, and he offered me the opportunity to join his editorial team. Little did I know that call would be the first of many in which Carl not only took time to discuss $J S R$ issues with me, but also caringly checked in on me and asked about how I was doing. During my time as Associate Editor, Carl has been a mentor who not only showed me the ropes, but who allowed me to play an active and significant role in $J S R$ initiatives and oversee manuscripts through the review process. One of the jobs I was tasked with doing early on was responding to JSR's e-mail inbox and assisting authors and reviewers through the review process. Although this was a relatively easy job, it led to more challenging opportunities that have had a positive impact on my career. I have appreciated the chance to work alongside and learn from Carl over the last 12 years of our JSR journey. I wish him all the best as he moves on to new journeys at the University of North Carolina-Greensboro as Dean of the School of Health and Human Sciences. I am confident his impact will be as significant there, as it has been to JSR.

I reached out to Carl's colleagues for their perspective on both working with him and his impact on JSR and the field of athletic health care. As the responses began to fill my e-mail inbox, I noticed common themes, none more obvious than this: "that Mattacola smile," as Craig Denegar, JSR board member, succinctly encapsulated
Carl's calm, professional, and friendly way of being. Buz Swanik, whose service as JSR Editor-in-Chief from 2004 to 2006 directly preceded Carl's, elaborated: "Carl's intelligent demeanor combined a sense of humor, objectivity, and open-minded approach to the many 'prickly' situations that arose with authors, reviewers, editorial board members, readers, and the publisher. Carl made it look easy."

Numerous colleagues, including Swanik, and JSR board members, Brent Arnold and Chad Starkey, thanked Carl for being a good friend as well as an exceptional colleague. Earning that praise from a colleague in the field is one thing, but obtaining it from your Managing Editor at the publisher is often a tougher task. Julia Glahn, a Human Kinetics Senior Managing Editor who worked with Carl for most of his tenure at JSR, had this to say: "Carl was a warm and enjoyable colleague to work with, and I always looked forward to his e-mails and phone calls." It is possible that higher praise has never been offered from a publisher to a field editor.

Kidding aside, Glahn, who has managed journals for more than 20 years and who also worked alongside two of Carl's predecessors, provided context for JSR's growth with Carl at the helm of the journal:

JSR has, unsurprisingly, changed a lot over the years. I remember [in the early days] our struggling to get a minimum of 80 printable pages for each $6 \times 9$-in quarterly issue of the journal. Carl grew $J S R$ to the point where we couldn't keep up with accepted manuscripts, even after the journal expanded to a larger format and a more frequent publication schedule. Whether that was through Carl's charm, tenacity, or both, it was a great success.

David Perrin, JSR's founding Editor-in-Chief who served from 1992 to 1995, provided additional perspective for how far the journal has come under Carl's leadership:

Carl is a former student and long-time colleague for whom I have great affection and admiration, so I was delighted with his appointment as JSR Editor 12 years ago. One always hopes a successor leads the enterprise to a higher level of excellence, and Carl has done just that. The index coverage of JSR has been dramatically expanded. The volume of submissions and quality of published papers has increased substantially. JSR's scholarly reputation and standing among all sports medicine journals has been enhanced. I am grateful to Carl for a job well done.

Perrin's praise was echoed by several others. "Carl's vision, passion, and leadership transformed JSR into a leading publication in athletic healthcare" said Starkey. "His efforts with this journal $(J S R)$ improved the quality of care provided by athletic trainers and our position in the healthcare setting." JSR Associate Editor Tamara Valovich McLeod added:

Carl was a visionary in his desire to provide clinicians with applicable information through the addition of the Critically Appraised Topic (CAT) papers. The initiation of this manuscript type in JSR came near the beginning of the formal evidence-based practice movement in athletic training and allowed authors an outlet to summarize important clinical 
questions relevant to practicing clinicians. The CAT manuscripts today continue to serve as a source of appraised best evidence for practicing clinicians.

Scott Lephart, who served as JSR Editor-in-Chief from 1996 to 1999 , also took note of the journal's significant growth as a result of Carl's stewardship: "The journal has taken on a more scholarly appearance and often is the publication of choice for scholars in the sport rehabilitation discipline."

An Editor-in-Chief must wear many hats. Beyond his strategic vision for growing the journal, Carl was also responsible to authors, reviewers, and board members. "Carl has provided important mentorship to reviewers and authors during his editorship" said Arnold. "More importantly, Carl has been a good friend to those of us who have had the privilege to serve on the JSR editorial board during his term." JSR board member Mitchell Cordova echoed Arnold:

Carl brought a strong, collaborative approach to improving and expanding JSR. In this regard, he greatly empowered his editorial board to think differently on how we can improve the practice of athletic training, and most importantly, how can we best disseminate this information to our readership. Carl's outgoing, genuine personality and positive outlook on the impact $J S R$ would continue to have on our profession was a pleasure to be a part of.

Carl's mentorship is a big part of the legacy he has created. JSR Associate Editor Matt Hoch is certainly appreciative of it:

Carl gave me the opportunity to serve as the Editorial Assistant for JSR in 2009, which in hindsight was one of the most influential experiences in my development as a scholar. Through my experience working with Carl and JSR, I was exposed to hundreds of manuscripts, researchers from around the world, and a behind the scenes view of the peer-review process. Carl's continuous desire to advance the reputation of $J S R$ has been inspiring and the constant climb of the journal's Impact Factor is a direct reflection of his leadership, dedication, and vision. Working with Carl on several of the Special Issues published during his tenure was particularly memorable and gratifying. These issues were logistically challenging and sometimes downright frustrating to assemble; however, they were well worth the positive impact the end products have had on the field. Although Carl has decided to pass the baton to the next Editor-in-Chief, his leadership has created a strong foundation for the journal's future success.

Lephart, who now serves as Dean of the University of Kentucky College of Health Sciences, where Carl has most recently served as Associate Dean, has worked side by side with Carl over the past 4 years. "I continue to be amazed by the volume of tasks and projects that Carl manages simultaneously," said Lephart, "not the least of which has been his role as the JSR Editor. . . . As Carl enters his next academic chapter as Dean of the School of Health and Human Sciences at the University of North Carolina at Greensboro, I am confident he will be as successful and productive as he has been for the past 20-plus years of his career. He has left JSR and the University of Kentucky in a better place than when he arrived."

Swanik provides a fitting note to close on when reflecting on the many successes of Carl's 12-plus years in charge of JSR: "Many of our readers have come to know and expect the steadfast, soft-spoken, and strategic leadership Carl provided. If I may speak for the many stakeholders, he is deeply admired and will be sorely missed. Thank you for your service."

Indeed! Best wishes to you, Carl, as you move on to the next challenging stage in your career, and thank you for your dedication to JSR.

Kellie C. Huxel Bliven, A.T. Still University 